\title{
THE UREASES OF PROTEUS STRAINS IN RELATION TO VIRULENCE FOR THE URINARY TRACT
}

\author{
B. W. Senior, N. C. Bradford* and D. S. Simpson* \\ Department of Bacteriology and *Department of Biochemical Medicine, University of Dundee, \\ Ninewells Hospital and Medical School, Dundee DD2 IUD
}

\section{Plates XXX-XXXII}

THE ENZYME urease is thought to play a major role as a virulence factor in urinary-tract infections with Proteus (Braude and Siemienski, 1960) although it may not be the only factor (Eudy, Burrous and Sigler, 1971). Urease degrades urea with release of ammonia which may cause damage and death to the renal epithelium, inactivation of complement, and conditions favouring the development of renal stones. Many of these effects can be prevented by the administration of urease inhibitors (Griffith and Musher, 1973; Griffith, Musher and Campbell, 1973; Aronson, Medalia and Griffel, 1974; Musher et al., 1975).

Phillips (1955) found wide variation in the pathogenicity of different strains of Proteus for the mouse kidney in vivo, and Senior (1979) has shown that particular proticine-production/sensitivity $(\mathrm{P} / \mathrm{S})$ types of $P$. mirabilis have a special affinity for the urinary tract whereas other $\mathrm{P} / \mathrm{S}$ types and other Proteus species are seldom incriminated in serious urinary-tract infections. The aim of this study was to determine whether or not these differences in pathogenicity among strains of Proteus were associated with differences in the types of ureases produced by these strains.

\section{MATERIALS AND METHODS}

Bacterial strains. Strains of Proteus species were isolated from specimens of urine and faeces sent for routine bacteriological examination. They were maintained as pure cultures on nutrient-agar slopes at $4^{\circ} \mathrm{C}$. In addition, two strains of $P$. mirabilis from boys with urinary-tract infection (Dr R. Maskell), five strains of $P$. rettgeri NCTC nos. 7475, 7476, 7477 and 7481 , and strain GRR3 (Dr D. Jones) and 17 strains of $P$. rettgeri of different $O$ serotypes (Dr J. Penner) were provided by colleagues. The species of each strain was determined or confirmed from the results of reactions in glucose, lactose, mannitol and sucrose peptone-water sugars, urea broth and tryptone water when tested for indole formation. P. mirabilis or P. vulgaris strains were typed by the method previously described (Senior 1977).

Growth of strains and preparation of sonic extracts. Preliminary investigations indicated that urease production by each strain was induced by urea. Cultures of strains actively producing urease were prepared therefore by 100 -fold dilution of overnight broth cultures (Oxoid CM67) into one of two media; these were (1) sterile $2.5 \%$ (w/v) nutrient broth (Oxoid CM67) in $0.1 \mathrm{M}$ sodium phosphate buffer $p \mathrm{H} 7.5$ supplemented with urea solution $(40 \% \mathrm{w} / \mathrm{v})$, sterilised by 
filtration, to a final concentration of $1 \%(\mathrm{w} / \mathrm{v})$ or $(2)$ pooled urine. This latter medium was prepared by adding $1 \mathrm{M} \mathrm{NaOH}$ to pooled urine until the $p \mathrm{H}$ reached 8.3. After standing overnight at $4^{\circ} \mathrm{C}$, the resulting alkali-precipitable material was removed by centrifugation. The $p \mathrm{H}$ of the clear supernatant urine was adjusted to 6.0 by the addition of $1 \mathrm{M} \mathrm{HCl}$ before sterilisation by filtration. Phenolphthalein solution $1 \%(\mathrm{w} / \mathrm{v})$ in propan-2-ol, was added to both media to a final concentration of $0.005 \%(\mathrm{w} / \mathrm{v})$.

The cultures were incubated with shaking at $37^{\circ} \mathrm{C}$ until alkalinity developed through urease production and degradation of urea; this stage was indicated by the phenolphthalein indicator starting to change from yellow to pink. At this point, the cells were harvested by centrifugation at $4^{\circ} \mathrm{C}$. The cell pellets were washed twice in PEM buffer (1mM sodium phosphate, $1 \mathrm{~mm}$ disodium EDTA and 5mM 2-mercaptoethanol $p \mathrm{H} \mathrm{7.0)}$ ) and resuspended in PEM buffer containing glycerol $20 \%(\mathrm{w} / \mathrm{v})$ and a trace of bromophenol blue dye. The cell suspensions were disrupted by sonication for $1 \mathrm{~min}$. in an ice-water bath. The cell debris was removed by centrifugation at $3500 \mathrm{~g}$ for $5 \mathrm{~min}$ and the supernate was stored at $-20^{\circ} \mathrm{C}$.

Assay of urease. The urease activity of the sonic extracts was determined by measuring, by the modified Berthelot reaction, the amount of ammonia formed from a standard excess amount of urea: $10-\mu$ portions of extract were added to $240 \mu$ of UPEM substrate (30mm urea, $20 \mathrm{~mm}$

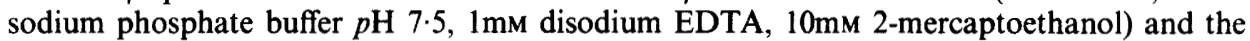
mixture incubated for $5 \mathrm{~min}$. at room temperature. The reaction was stopped by the addition of phenol nitroprusside solution $0.5 \mathrm{ml}$, alkaline hypochlorite $0.5 \mathrm{ml}$ and distilled water $2.5 \mathrm{ml}$. After $5 \mathrm{~min}$. at room temperature, the intensity of the developed blue colour was measured at $570 \mathrm{~nm}$ and compared with that given by standard solutions of ammonium chloride. One unit of urease was defined as the amount of extract required to liberate $1 \mu \mathrm{mol}$ of ammonia in $5 \mathrm{~min}$. at room temperature in the above conditions.

Analysis of urease by polyacrylamide-gel electrophoresis. Sonic extracts containing urease were analysed by high- $p \mathrm{H}$ discontinuous polyacrylamide-gel electrophoresis. One unit of urease was applied to each slot of a slab gel comprising a resolving gel of acrylamide $6 \%(\mathrm{w} / \mathrm{v})$ and $\mathrm{N}, \mathrm{N}^{\prime}$-methylene-bis-acrylamide $0.3 \%(\mathrm{w} / \mathrm{v})$ in $0.375 \mathrm{M}$ Tris $\mathrm{HCl} p \mathrm{H} 8.9,1 \mathrm{~mm}$ disodium EDTA and 5mM 2-mercaptoethanol and a stacking gel of acrylamide $3 \%(\mathrm{w} / \mathrm{v}), \mathrm{N}, \mathrm{N}^{\prime}$-methylenebis-acrylamide $0.15 \%(\mathrm{w} / \mathrm{v})$ in $0.0625 \mathrm{M}$ Tris $\mathrm{HCl} p \mathrm{H} 6.7$, and overlaid with electrode buffer $\left(0.38 \mathrm{M}\right.$ glycine in $0.005 \mathrm{M}$ Tris). Electrophoresis was usually done at $75 \mathrm{~V}$ for $16 \mathrm{~h}$ at $4{ }^{\circ} \mathrm{C}$. The gels were then gently washed at $4^{\circ} \mathrm{C}$ in several changes of an aqueous solution of disodium EDTA $0.1 \%(\mathrm{w} / \mathrm{v})$ and cresol-red indicator $0.02 \%(\mathrm{v} / \mathrm{v})$ until the gel just became yellow, indicating neutral or slightly acid conditions. Gels were developed by discarding the washing solution and immersing them in a small volume of urea $1.5 \%(\mathrm{w} / \mathrm{v})$ in water. Because urea is the specific substrate for urease, active urease isoenzymes were deduced to exist in areas where cherry-red bands appeared against the yellow background by the local production of alkali as a result of enzymic degradation of urea.

The developed gels were recorded by immediate photography with a Nikon F2 camera fitted with a Nikon XI dark-green filter. The film, Ilford Pan F, was developed in ID 11 developer for $8 \mathrm{~min}$. at $20^{\circ} \mathrm{C}$. To detect traces of urease isoenzymes, it was necessary to prolong the period of immersion in urea. These conditions, however, led to a broadening of the major bands and this eventually masked the location of minor bands. To prevent this and yet permit detection of minor bands, when major bands had been located, the gels were cut. The portion of the gel containing the major bands was removed from the urea solution and stored at $4^{\circ} \mathrm{C}$ in the EDTA-cresol red washing solution. When the minor bands could be clearly seen, the portions of the gel were reassembled and photographed together.

\section{RESULTS}

Initial experiments showed that the electrophoretic pattern of urease isoenzymes of strains grown in phosphate-buffered broth containing urea were indistinguishable from those given by the same strains when grown in treated urine. Thus the differences in enzyme patterns observed, within a species and 
between the different Proteus species, cannot be attributed to variation in cultural conditions.

\section{P. morgani urease}

The ureases of 12 strains of $P$. morgani, isolated from the urine or faeces of 12 healthy male and female patients, ranging in age from 4 months to 86 years, were examined. Electrophoresis failed to reveal any differences between the urease isoenzymes of these strains. Each strain produced three isoenzymes (fig. 1a); the fastest moving isoenzyme, also called the main band or $\alpha$ urease, (Blattler, Contaxis and Reithel, 1967) was extremely active and rapidly appeared during the development of the gel. It was followed by $\beta$ and $\gamma$ ureases equidistant behind $\alpha$. In some instances it seemed that the $\alpha$ urease might be a double band and this was possibly also true for the $\beta$ and $\gamma$ isoenzymes. All three isoenzymes seemed to be of high molecular weight because they did not move far into the gel. Further analysis of these isoenzymes in $5 \%$ acrylamide gels run overnight at $140 \mathrm{~V}$ gave better separation (fig. 1b).

\section{$P$. rettgeri urease}

The ureases of 26 strains of different serotypes of $P$. rettgeri were examined. Although some strains of different $O$ serotype gave the same electrophoretic pattern, there was considerable diversity among other strains in their urease isoenzymes, and representatives of the different types found are shown in fig. 2a. The $\alpha$ urease isoenzymes of different strains electrophoresed over a range of positions. When comparisons were made between Proteus species into the mobility of their $\alpha$ urease, it was clear (figs. $2 b$ and $2 c$ ) that, in general, those of $P$. rettgeri were the furthest moving, followed by those of $P$. vulgaris, $P$. mirabilis and $P$. morgani. After the development of the $\alpha$-urease band, the next isoenzyme to appear was one that electrophoresed only a short distance into the gel, $\omega$ urease. Only some strains of $P$. rettger $i$ appeared to possess this isoenzyme, which banded in a position close to that of the $\alpha$ urease of $P$. morgani (fig. 2a). Further analysis (fig. 2c) showed that the $\omega$ urease banded in a position between the $\alpha$ and $\beta$ ureases of $P$. morgani. Occasionally, the $\alpha$ and the $\omega$ urease bands of some strains each appeared to be double bands (fig. $2 \mathrm{c}$ slots 2, 4, 6). Prolonged development of the gels revealed minor isoenzymes (usually two) behind the $\alpha$ urease and there appeared to be differences between the strains in the relative proportions of the two components of these minor isoenzymes (fig. 2a).

\section{$P$. vulgaris urease}

The ureases of 12 strains of $P$. vulgaris belonging to nine different $\mathrm{P} / \mathrm{S}$ types were examined. All appeared to give similar electrophoretic patterns but there was some variation between the strains in the mobility of the $\alpha$ urease (fig. 3). 
One strain, P. vulgaris F35865 (fig. 3, slot 11) was unusual in possessing a very mobile $\alpha$ urease which moved considerably faster than that of the other strains of $P$. vulgaris and even faster than that of one P. rettgeri strain (fig. $2 \mathrm{~b}$, slots 3 and 4). There was no correlation between mobility of the $\alpha$ urease and the $P / S$ type of a strain. Prolonged development of the gels revealed two minor isoenzymes behind the $\alpha$ isoenzyme (figs. 3 and $4 c$ ).

\section{$P$. mirabilis urease}

The ureases of 33 strains of $P$. mirabilis were examined; 16 strains were of those $\mathrm{P} / \mathrm{S}$ types commonly found in faeces and in urine (Senior, 1979), i.e., P/S types $\mathrm{P} 0 / \mathrm{S} 4, \mathrm{P} 0 / \mathrm{S} 7, \mathrm{P} 1 / \mathrm{S} 0$ and $\mathrm{P} 2 / \mathrm{S} 1$, and included local and distant isolates from the faeces of healthy patients and the urine of patients with urinary-tract infections; 17 strains were of $\mathrm{P} / \mathrm{S}$ types $\mathrm{P} 3 / \mathrm{S} 1,8, \mathrm{P} 3 / \mathrm{S} 1,13$ and $\mathrm{P} 3 / \mathrm{S} 1,8,13$ which are known to have a special affinity for the urinary tract (Senior, 1979), 15 of them being isolated from different patients with severe urinary-tract infection and two from the stools of healthy patients. The $\alpha$-urease isoenzymes of 30 of the strains were electrophoretically indistinguishable from each other but three strains, F51259 (P0/S4) and F35549 (P0/S7) both from faeces and 1427/77 (P0/S7) from urine, had an $\alpha$ urease that consistently ran faster than that of the other strains (fig. 4a). Other strains having $\mathrm{P} / \mathrm{S}$ types the same as those possessing "fast" $\alpha$ urease were found to have "normal" $\alpha$ urease. The $\alpha$ urease isoenzymes of $P$. mirabilis were very similar in mobility to those of many strains of P. vulgaris (fig. 4b). Prolonged development of the gels revealed two minor isoenzymes which appeared to be different from those of $P$. vulgaris in that the latter were evenly spaced behind the $\alpha$ urease whereas those of $P$. mirabilis appeared to be grouped together (fig. 4c).

Although minor differences were observed in the urease isoenzyme patterns of some strains within a species, the greatest differences were observed between strains representing the different Proteus species. The patterns of urease isoenzymes fell into four groups: (1) that given by strains of P. morgani, (2) that given by strains of $P$. rettgeri and (3) that given by strains of $P$. vulgaris, which was similar to (4) that given by strains of $P$. mirabilis (fig. 5).

\section{DisCUSSION}

Most of our understanding of urease has come from research on jack-bean urease, whereas little is known about the enzyme produced by strains of Proteus despite the fact the proteus urease is considered to be a major factor in the development of pyelonephritis (Braude, Shapiro and Siemienski, 1959). Guo and Liu (1965) made a limited study of the serological specificities of Proteus ureases and found those of $P$. mirabilis, $P$. vulgaris and $P$. rettgeri to be serologically indistinguishable from each other and quite different from that of $P$. morgani. The results presented here substantiate the view that $P$. morgani urease is distinct from that of other Proteus species and even though the ureases of $P$. mirabilis, $P$. vulgaris and $P$. rettgeri may be serologically indistinguish- 


\section{Proteus UREASES AND VIRULENCE}
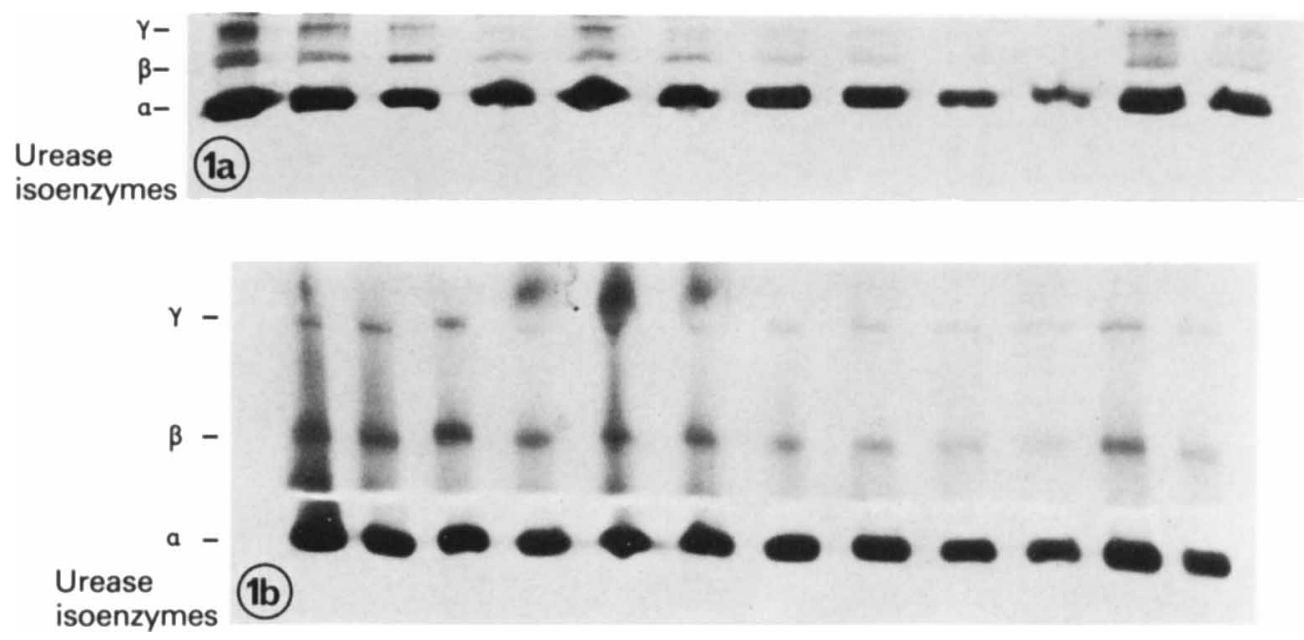

FIG. 1.-The urease isoenzymes of strains of $P$. morgani after overnight electrophoresis on (a) $6 \%$ polyacrylamide gels at $75 \mathrm{~V}$ and (b) $5 \%$ polyacrylamide gels at $140 \mathrm{~V}$.

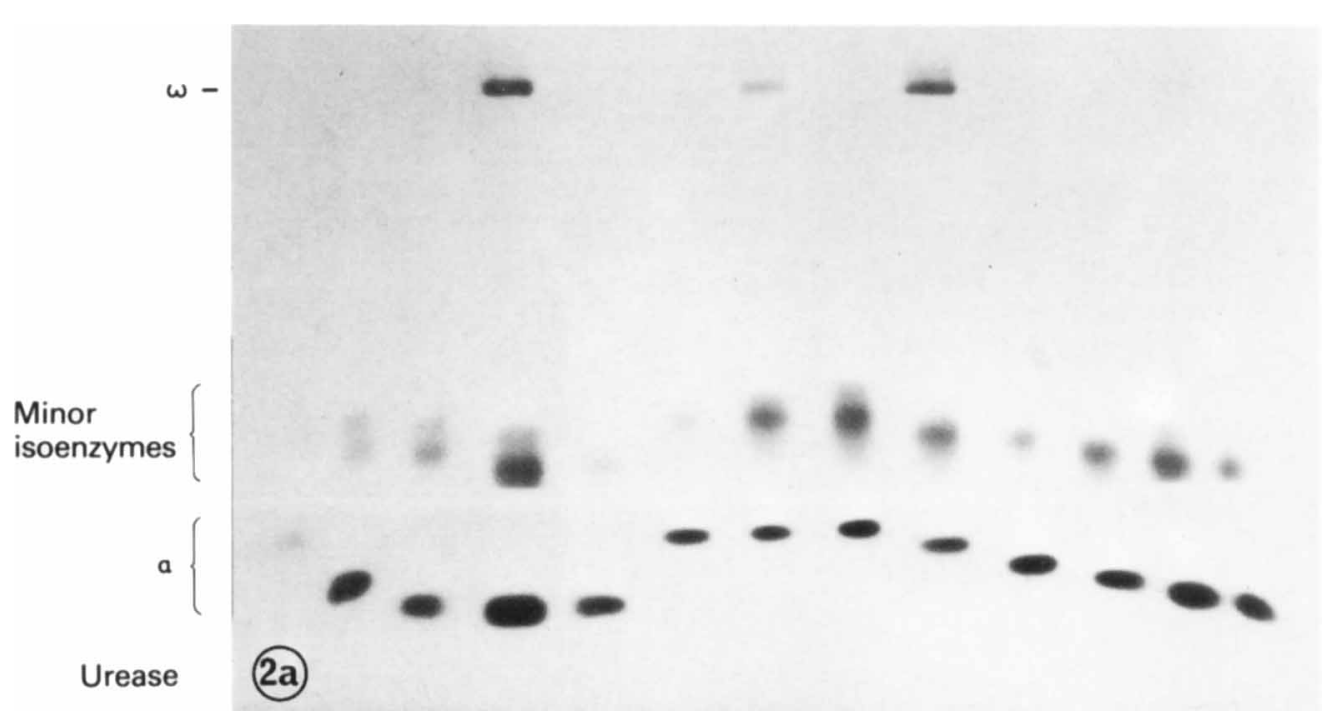

FIG. 2a.-The urease isoenzymes of $P$. rettgeri strains of different $O$ serotype. 


\section{Proteus uREASES AND VIRULENCE}

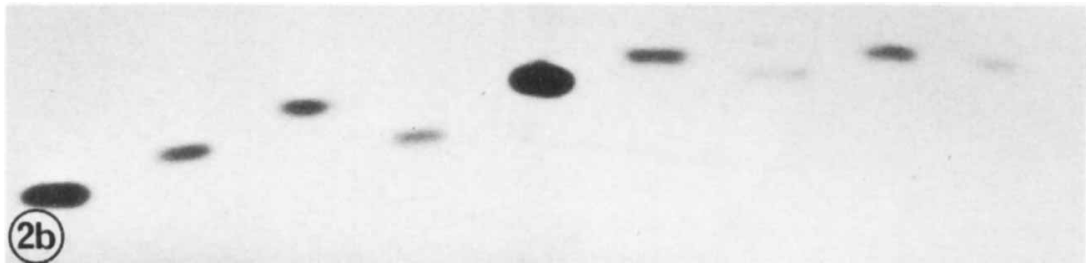

FIG. 2b.-Comparison of the mobilities of a range of $\alpha$ urease isoenzymes isolated from strains of (left to right) 1-3 P. rettgeri, 4-6 P. vulgaris, 7-9 P. mirabilis.

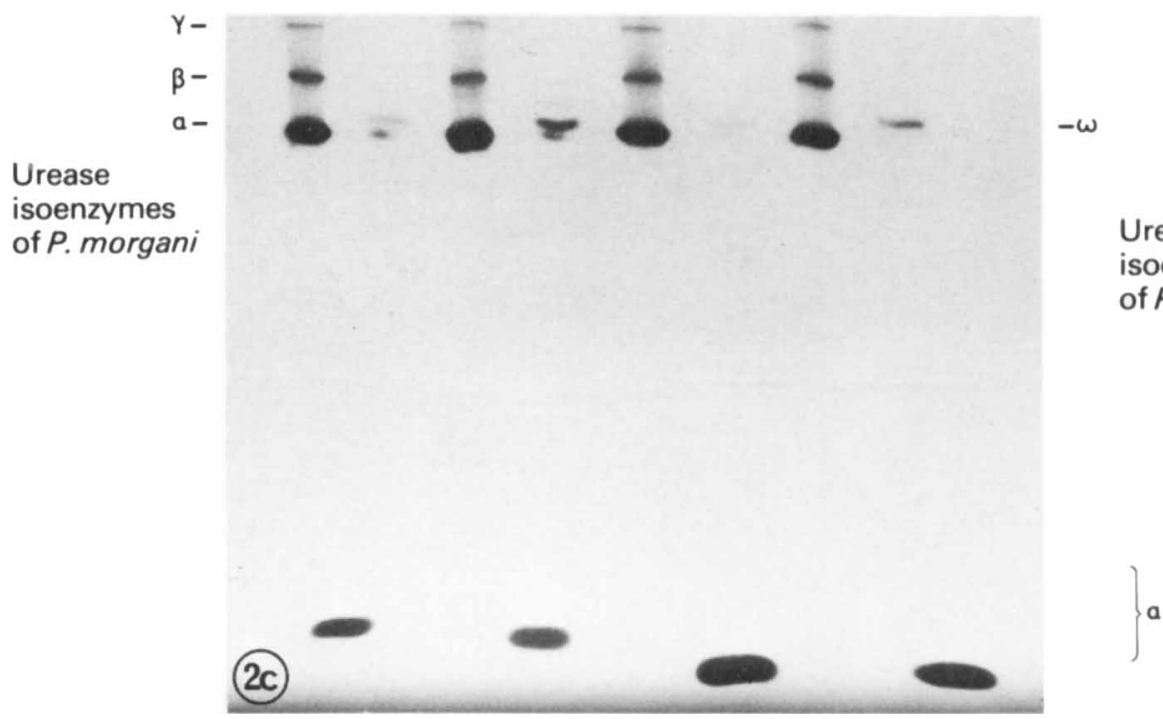

FIG. 2c.--Comparison of the mobility of the $\omega$ urease isoenzyme from four strains of $P$. rettgeri with that of the urease isoenzymes of $P$. morgani

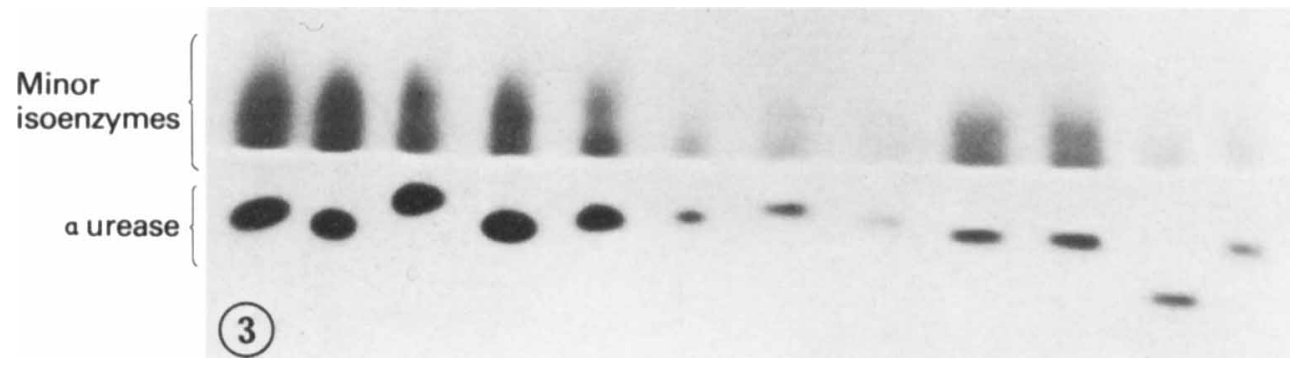

FIG. 3. - The urease isoenzymes of strains of $P$. vulgaris of different $P / S$ type. The urease from strain F35865 was placed in the second slot from the right. 


\section{Proteus UREASES AND VIRULENCE}
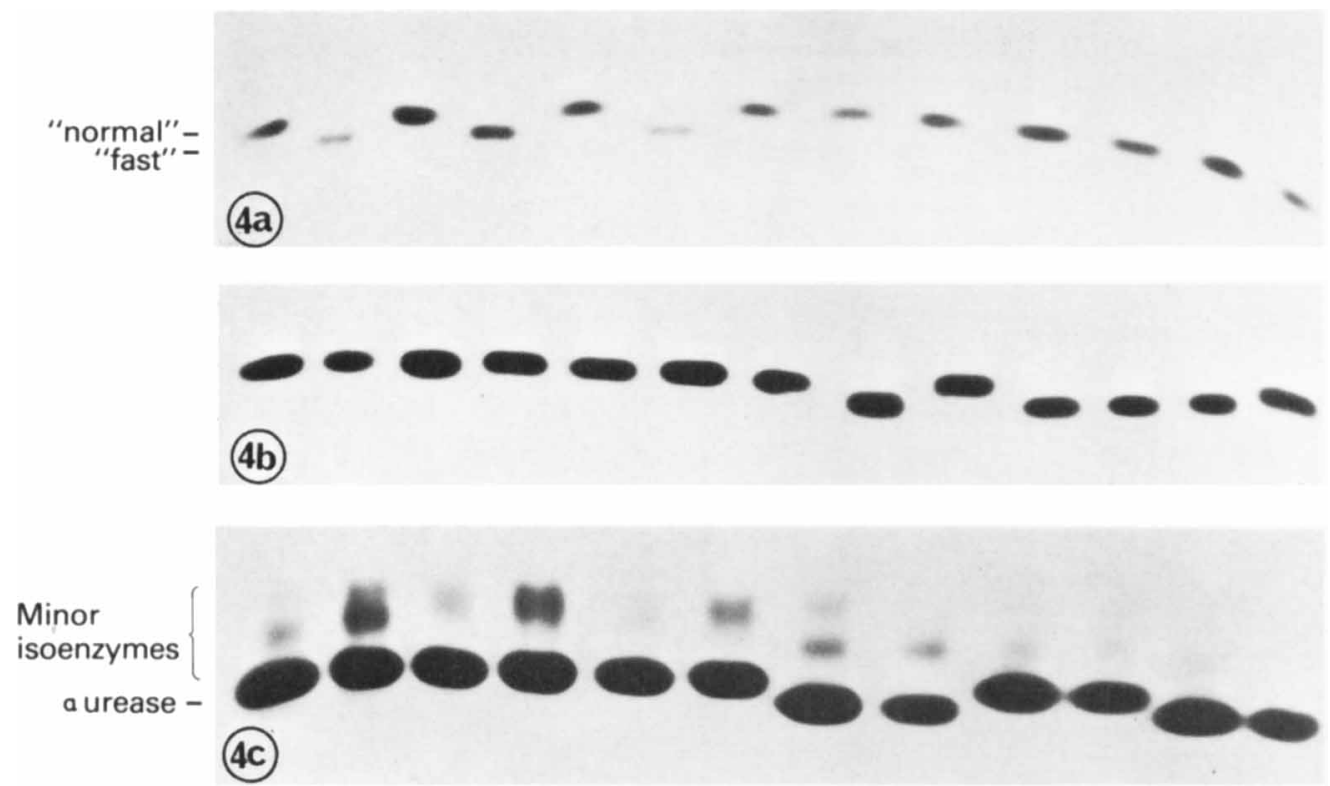

FIG. 4.-(a) The $\alpha$ urease isoenzymes of $P$. mirabilis strains of different $P / S$ type. (b) Comparison of the mobilities of the $\alpha$ urease isoenzymes of (left to right) 1-7 P. mirabilis and 8-13P. vulgaris strains of different $\mathrm{P} / \mathrm{S}$ type. (c) Comparison between the urease isoenzyme pattern of (left to right) 1-6 $P$. mirabilis and 7-12 P. vulgaris strains of different $\mathrm{P} / \mathrm{S}$ type.

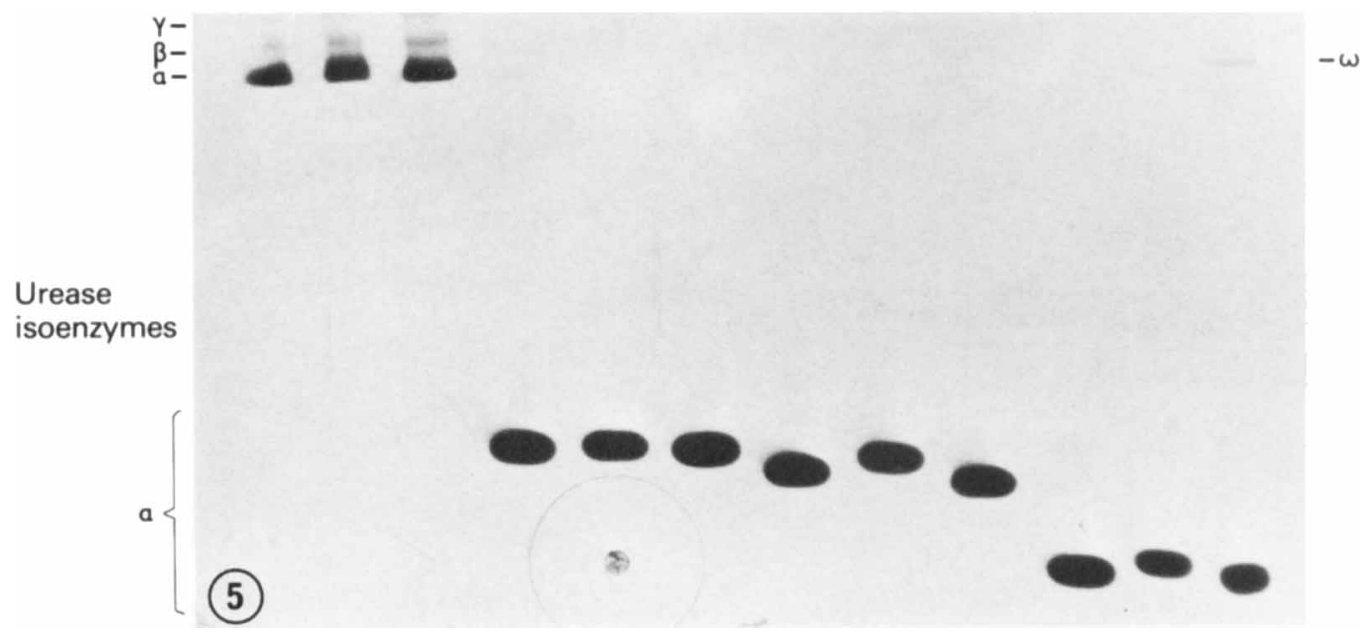

FIG. 5.-The differences in mobility of the urease isoenzymes among the different Proteus species. Left to right 1-3 P. morgani, 4-6 P. vulgaris, 7-9 P. mirabilis 10-12 P. rettgeri. 
able, their isoenzyme patterns as determined by gel electrophoresis suggest that they are quite different from each other.

Jack-bean urease can be rapidly and reversibly dissociated into several catalytically active forms, dissociation being favoured by conditions of low ionic strength, high $p \mathrm{H}$ and high concentrations of reducing agents (Blattler $e t$ al., 1967; Fishbein, Spears and Scurzi, 1969). Because of the standard ways in which all enzyme extracts were prepared, stored and run it is highly improbable that these explanations could account for the variation in urease isoenzyme patterns found within and between the Proteus species examined in this study. It is more probable that the different isoenzyme patterns of different Proteus species are produced by isoenzymes that have dissociated from genetically different enzymes.

A recent survey of the DNA relatedness between strains of Proteus species (Brenner et al., 1978) has suggested that $P$. morgani strains form a single unique group of closely similar organisms which are quite different from other Proteus species, whereas $P$. rettgeri strains form another group with three different but related groups of strains within it. P. mirabilis strains form another distinct homogenous group which, while different from other groups, is partially related to the $P$. vulgaris group of strains which comprise two related groups of organisms. The results of urease isoenzyme patterns agree very closely with this classification scheme. The ureases of $P$. morgani were indistinguishable from each other but quite different from those of other Proteus species. The greatest diversity of isoenzymes was seen among $P$. rettgeri strains and, considering $\omega$-urease isoenzyme alone, two distinct groups of strains could be defined - those that possess the isoenzyme and those that do not. There was less variation in the enzyme patterns of the different $P$. vulgaris strains, some of which appeared to be very similar to those of $P$. mirabilis, the latter forming, almost without exception, a single pattern of urease isoenzymes.

The absence of any correlation between $\mathrm{P} / \mathrm{S}$ type and urease isoenzyme pattern among the large number of $P$. mirabilis strains examined suggests that the variation in pathogenicity for the urinary tract among strains with different $\mathrm{P} / \mathrm{S}$ types is not related to the types of ureases that the strains form. It may be related, however, to the factors that control urease production in these strains and this problem is to be investigated.

\section{SUMMARY}

The ureases produced by a large number of strains of different Proteus species, some of which were known to have a special affinity for the urinary tract, were examined by polyacrylamide-gel electrophoresis. Each Proteus strain gave a pattern of urease isoenzymes that was characteristic and unique to its species although strains of $P$. mirabilis and $P$. vulgaris gave isoenzyme patterns that were closely similar. There was some minor variation in the patterns of. urease isoenzymes even between strains of the same species. This was most noticeable among $P$. rettgeri strains and to a lesser extent among 
$P$. vulgaris strains. No correlation was found between the types of ureases a strain produced and its pathogenicity for the urinary tract.

We are grateful to the staff of the Medical Photography Department, Ninewells Hospital, Dundee for their technical assistance and to Dr R. M. Maskell, Public Health Laboratory, St Mary's General Hospital, Portsmouth, Dr D. Jones, Department of Microbiology, University of Leicester, and Dr J. L. Penner, Department of Medical Microbiology, University of Toronto, for the gift of strains.

\section{REFERENCES}

Aronson, M., Medalia, O. and Griffel, B. 1974. Prevention of ascending pyelonephritis in mice by urease inhibitors. Nephron, 12,94.

Blattler, D. P., Contaxis, C. C. ANd Reithel, F. J. 1967. Dissociation of urease by glycol and glycerol. Nature, Lond., 216, 274.

Braude, A. I., Shapiro, A. P. AND Siemienski, J. 1959. Hematogenous pyelonephritis in rats. iii. Relationship of bacterial species to the pathogenesis of acute pyelonephritis. J. Bact. $77,270$.

Braude, A. I. AND SiemiensKi, J. 1960. Role of bacterial urease in experimental pyelonephritis. J. Bact., 80, 171.

Brenner, D. J., Farmer, J. J., Fanning, G. R., Steigerwalt, A. G., Klyk ken, P., Wathen, H. G., Hickman, F. W. ANd EwING, W. H. 1978. Deoxyribonucleic acid relatedness of Proteus and Providencia species. Int. J. syst. Bact., 28, 269.

Eudy, W. W., Burrous, S. E. AND Sigler, F. W. 1971. Renal lysozyme levels in animals developing "sterile pyelonephritis". Infect. Immun., 4, 269.

FishbeIN, W. N., SpearS, C. L. AND SCURzI, W. 1969. Spectrum of urease isozymes: genetic, polymeric and conformeric. Nature, Lond., 233, 191.

Griffith, D. P. AND Musher, D. M. 1973. Prevention of infected urinary stones by urease inhibition. Invest. Urol., 11, 228.

Griffith, D. P., Musher, D. M. and Campbell, J. W. 1973. Inhibition of bacterial urease. Invest. Urol., 11, 234.

Guo, M. M. S. AND Liu, P. V. 1965. Serological specificities of ureases of Proteus species. J. gen. Microbiol., 38, 417.

Musher, D. M., Griffith, D. P., YaWn, D. and Rossen, R. D. 1975 . Role of urease in pyelonephritis resulting from urinary tract infection with Proteus. J. infect. Dis., 131, 177.

PhILLIPS, J. E. 1955. The experimental pathogenicity in mice of strains of Proteus of animal origin. J. Hyg., Camb., 53, 212.

SENIOR, B. W. 1977. Typing of Proteus strains by proticine production and sensitivity. J. med. Microbiol., 10, 7.

SENIOR, B. W. 1979. The special affinity of particular types of Proteus mirabilis for the urinary tract. J. med. Microbiol., 12, 1. 